\title{
A escola e os educadores em tempo de ciclos e progressão continuada: uma análise das experiências no estado de São Paulo
}

Márcia Aparecida Jacomini

Faculdade do Taboão da Serra

\section{Resumo}

Neste artigo discute-se a atuação dos educadores no processo de implementação dos ciclos e da progressão continuada nas redes públicas de ensino municipal e estadual de São Paulo em quatro momentos distintos: na Reforma de 67/68, na implantação do Ciclo Básico de Alfabetização em 1983/84, na instituição do regime de progressão continuada em 1998, (rede estadual paulista), e na adoção dos ciclos e da progressão continuada em 1992 (rede municipal de ensino da cidade de São Paulo). Considera-se que a efetivação das políticas públicas educacionais depende, em grande medida, da participação de seus principais protagonistas - os educadores. Por isso é importante saber como determinados condicionantes influenciam as concepções e a atuação dos educadores perante os ciclos e a progressão continuada. Tendo como referência quatro experiências realizadas em distintos momentos e com características particulares, busca-se analisar com base nos condicionantes materiais, ideológicos e institucionais-pedagógicos a resistência dos educadores em relação aos ciclos e à progressão continuada. Busca-se compreender como esses condicionantes interagem na determinação de uma concepção, muito comum entre os educadores, de que os ciclos e a progressão continuada são importantes na democratização do ensino e da aprendizagem, não obstante não existirem condições materiais e institucionaispedagógicas para implementá-los. Sendo assim, eles contribuiriam para deteriorar ainda mais a qualidade do ensino. Com isso, querse neste artigo elucidar uma das controvérsias que envolvem os ciclos e a progressão continuada: a resistência dos educadores em aceitá-los e implementá-los.

\section{Palavras-chave}

Ciclo - Progressão continuada - Educadores - Condicionantes.

Correspondência:

Márcia Aparecida Jacomini

R. José Antonio Coelho, 300/135 A

04011-060 — São Paulo — SP

e-mail: marciajacomini@uol.com.br 


\title{
The school and the educators in times of learning cycles and continued progression: an analysis of the experiences in the State of São Paulo
}

Márcia Aparecida Jacomini

Faculdade do Taboão da Serra

\begin{abstract}
This article discusses the role of educators in the process of establishing and implementing learning cycles and continued progression in the city and state public school networks of São Paulo in four different moments: in the 1967/1968 Reform, in the implementation of the Literacy Basic Cycle in 1983/1984, in the creation of the regime of continued progression in 1998 (state public network), and in the adoption of the learning cycles and continued progression in 1992 (city of São Paulo public network). It is assumed that the realization of public policies in education depends to a large extent upon the participation of their main protagonists - the educators. It is thus important to know how certain factors influence the conceptions and the actions of educators with respect to learning cycles and continued progression. We seek to understand how these factors interact to determine the conception, very common among educators, that learning cycles and continued progression are important for the democratization of schooling and learning, but that the material and institutional/pedagogical conditions to implement them are lacking. In that way, they contribute to deteriorate even further the quality of teaching. The goal here is to help clarifying one of the controversies surrounding learning cycles and continued progression: the resistance of educators in accepting and implementing this educational proposal.
\end{abstract}

\section{Keywords}

Learning cycles - Continued progression - Educators - Factors.

Contact:

Márcia Aparecida Jacomini

R. José Antonio Coelho, 300/135 A

04011-060 - São Paulo - SP

e-mail: marciajacomini@uol.com.br 


\section{Introdução}

A temática dos ciclos e da progressão continuada tem provocado acalorados debates entre educadores, pesquisadores e membros das secretarias municipais e estaduais de Educação que implantaram essa forma de organização do ensino nas últimas décadas. Historicamente, a seriação foi quase que exclusivamente a organização de ensino nos sistemas educacional público e privado. Em consonância com uma estrutura social que opera conforme o princípio da seletividade e da exclusão, a escola seriada cumpriu a função de reprodutora da estratificação social. Ela reforçou, apesar de não se propor a isso estruturalmente, por meio da reprovação e da evasão, o lugar "reservado" às diferentes classes sociais. Salvo raras exceções, os repetentes e evadidos da escola são os mesmos excluídos socialmente. Nesse sentido, a escola pública ainda não conseguiu construir uma dinâmica interna que pudesse contrapor-se à dinâmica social e consolidar-se, efetivamente, como um espaço público e democrático.

Sem negar, a princípio, que a escola como instituição estatal desempenha a função de reprodutora tanto da infra-estrutura quanto da superestrutura da sociedade capitalista, busca-se a partir do sentido ampliado de Estado, desenvolvido por Antonio Gramsci, a escola que possa vir a exercer um papel especial na produção de singularidades educacionais e sociais que propiciem a democratização do conhecimento e da sociedade.

A dinâmica paradoxal que a escola desenvolve, ao lidar com as contradições inerentes à produção capitalista, é o locus no qual as diferentes forças políticas e sociais que atuam na sociedade civil disputam e imputam-lhe uma prática miscigenada, a seu turno, por elementos conservadores e progressistas.

É no âmago do caráter contraditório das práticas educativas escolares que estão as possibilidades dos setores progressistas democratizarem ao máximo a escola e ampliarem suas possibilidades de ser um espaço de reflexão, ação, e transformação. Pois,

a práxis (...) é reflexão e ação dos homens sobre o mundo para transformá-lo. Sem ela, é impossível a superação da contradição opressor-oprimidos. (Freire, 1987, p. 38)

Em consonância com a perspectiva da escola romper as formas organizativas que privilegiam processos seletivos, os ciclos apresentam-se como proposta alternativa para se pensar o tempo, o espaço, os conteúdos e as metodologias que compõem o processo de ensino e aprendizagem. As pesquisas no campo da aprendizagem e do desenvolvimento humanos oferecem subsidios que validam outras formas de organizar os tempos e os conteúdos escolares, de modo a se adequarem ao desenvolvimento e a aprendizagem dos educandos sem interrupções a cada ano letivo, que contribuem para a democratização do conhecimento e a superação ou, pelo menos, a minimização das características excludentes que a escola pública ainda mantém.

Entre os muitos aspectos sob os quais os ciclos e a progressão continuada podem ser discutidos, elegeu-se, para este artigo, uma análise sobre o que os educadores pensam sobre essa forma de organização do ensino e como construíram tal concepção. Busca-se, com isso, contribuir para elucidar uma das principais controvérsias que envolvem os ciclos e a progressão continuada: a resistência dos educadores $^{1}$ em aceitar e implementar essa proposta educacional. Entende-se que o posicionamento dos educadores e a concepção que pais e alunos apresentam sobre os ciclos e a progressão continuada são fatores determinantes no processo de sua implementação na perspectiva de democratizar a escola e o conhecimento construído e sistematizado pela humanidade.

1. Sobre a resistência dos educadores à promoção consultar Paro (2001), Fusari et al. (2001) e Jacomini (2002). 


\section{Promoção automática, ciclos e progressão continuada: um breve histórico}

A análise de propostas educacionais nos remete à compreensão das idéias e ideais que subsidiam sua formulação. A construção de escolas como instituições responsáveis pela educação das novas gerações foi resultado da ineficácia da tradicional educação informal que era transmitida pelas famílias e comunidades. A educação escolar, que em sua origem estava restrita às camadas dirigentes da sociedade, passou, a partir dos séculos XIX e XX, a ser reivindicada pela população, universalizando-se nos chamados países desenvolvidos no século passado e ampliando-se em busca da universalização nos países em desenvolvimento e subdesenvolvidos nas últimas décadas do século XX e início do século XXI.

Pode-se dizer, grosso modo, que a seriação como forma de organização do ensino adotada na maioria dos sistemas educacionais no mundo respondeu às concepções que entendiam a escola como representante do saber, sendo sua principal função a transmissão do conhecimento e a seleção anual dos "bemsucedidos”, para continuarem os estudos. Os conteúdos organizados em séries deveriam ser aprendidos durante o ano letivo. Aqueles que conseguiam, segundo a avaliação da escola, eram promovidos para a série seguinte, os demais repetiam a mesma série. Como os conteúdos escolhidos, as metodologias adotadas e o processo de avaliação quase não são modificados, quase sempre acontece a repetência recorrente e conseqüente evasão escolar.

As idéias e os ideais por trás dessa forma de organizar o ensino, mesmo que não explícitos, podem ser entendidos como aqueles que apregoam que nem todos podem usufruir o conhecimento construído pelo homem no principal espaço de aprendizagem e de reflexão: a escola. Dessa forma, a escola pública inicialmente organizada para atender um determinado tipo de aluno, geralmente aquele proveni- ente das classes média e alta, não conseguiu democratizar a aprendizagem assim que as camadas populares passaram a ter acesso a ela. Foi nesse contexto que educadores progressistas e preocupados com a exclusão escolar em relação à população de baixa renda construíram propostas que subverteram a ordem consolidada e vigente na escola.

Podem-se dividir em quatro grandes momentos as discussões e experiências de ensino não seriado no Brasil. Os primeiros registros datam da década de 1920: a defesa do professor Sampaio Dória da adoção de promoção automática no ensino primário paulista, com o objetivo de ampliar o atendimento escolar aos ingressantes, e a proposta de promoção em massa, do então diretor-geral do ensino, Oscar Thompson. Essa discussão não contou com uma elaboração mais consistente acerca da aprendizagem como direito de todos e não teve repercussões práticas. 0 segundo momento ocorreu na década de 1950, quando os educadores Dante Moreira Leite e Almeida Júnior, tendo como referência as experiências de ciclos e progressão continuada inglesas iniciadas em 1944, e a americana, nos estados de Michigan e Kentucky, visitados por Almeida Júnior, defenderam a adoção da promoção continuada, na época chamada de promoção automática, compreendendo-a como uma forma de respeito e responsabilidade diante das diferenças e necessidades individuais na realização de um ensino e de uma aprendizagem para todos (ver Almeida Júnior, 1959).

Numa reflexão sobre as razões que levam as escolas a aceitarem a reprovação não obstante as conseqüências tão desastrosas que ela traz, Dante Moreira Leite apresentou três razões fundamentais: primeira, a escola é uma instituição tradicionalmente seletiva; segunda, concebe-se que as classes devam ser homogêneas; terceira, compreende-se que o prêmio e o castigo são formas de provocar ou acelerar a aprendizagem. Então, como proposta de superação dessa concepção, acreditava 
que duas medidas básicas precisam ser defendidas e efetivadas: primeira, a organização de um currículo adequado ao desenvolvimento do aluno; segunda, a instituição da promoção automática. (1959, p. 195-196)

Os debates transcorridos na década de 1950 resultaram na implantação de experiências de organização do ensino em ciclos e de progressão continuada nos anos 1960 em algumas redes de ensino. Essas experiências estavam amparadas legalmente na primeira Lei de Diretrizes e Base da Educação Nacional (LDB), Lei $n^{\circ} 4.024 / 61$. De acordo com o artigo 104 desta lei, era permitida a organização de cursos ou escolas com currículo, métodos e períodos escolares próprios em caráter experimental. Tendo como referência esta lei e algumas mudanças que começavam a ser introduzidas em função dos debates sobre a necessidade de se adotarem medidas que contribuíssem para a superação do fracasso escolar, que se expressava nos altos índices de reprovação e evasão escolares, alguns estados brasileiros adotaram organizações alternativas à seriação. No estado do Rio de Janeiro, em 1967, organizou-se o ensino combinando faixa etária e nível de escolaridade. No estado de São Paulo o ensino primário foi organizado em dois níveis $\left(1^{\mathrm{a}}\right.$ e $2^{\mathrm{a}}$; $3^{\text {a e }} 4^{\text {a }}$ séries), sendo adotada a progressão continuada entre as séries de cada nível em 1968. Também em 1968, adotou-se em Pernambuco a organização por níveis. 0 Sistema de Avanços Progressivos (SAP) foi adotado em Santa Catarina, abolindo a reprovação ao longo das quatro primeiras e das quatro últimas séries, em 1970. Já havia sido adotada, neste estado, com base nos dispositivos constitucionais de 1967, a obrigatoriedade de oito anos de escolaridade na rede estadual de ensino (Plano Estadual de Educação de 1969). Também em 1970, adotou-se o Sistema de Avanços Progressivos em Minas Gerais (Barreto; Mitrulis, 1999; Mainardes, 2001; Jacomini, 2002).

0 terceiro momento de adoção de ciclos e progressão continuada deu-se após a Lei
5.692/71, que instituiu e organizou o ensino de primeiro e segundo graus, e manteve, de acordo com o artigo 14 , parágrafo $4^{\circ}$, a possibilidade dos sistemas de ensino se organizarem de forma não seriada, em caráter experimental, sendo necessária, para o seu funcionamento, a autorização do Conselho Estadual de Educação. Algumas experiências implantadas após a Lei $n^{\circ}$ 5.692/71 e antes da nova LDB - Lei no 9.394/ 96 permanecem até hoje. Em 1978, foi implantado no Distrito Federal a proposta de Avanços Progressivos, e no estado do Rio de Janeiro adotou-se o Bloco Único em 1979. Na década de 1980, foi adotado em alguns estados o Ciclo Básico de Alfabetização (CBA): São Paulo em 1984, Minas Gerais em 1985, Paraná e Goiás em 1988. Na década de 1990, ainda antes da nova LDB, alguns municípios incorporaram os ciclos e a progressão continuada, sendo que essas experiências se estenderam para os oitos anos do ensino fundamental: São Paulo (1992), Escola Plural em Belo Horizonte (1994) e a Escola Cidadã em Porto Alegre (1995) (Jacomini, 2002).

0 quarto momento constitui-se das experiências implantadas a partir da nova LDB. Tendo como referências as experiências anteriores e a necessidade premente de garantir aprendizagem aos milhares de alunos que têm acesso à escola pública, a Lei $n^{\circ}$ 9.394/96 instituiu os ciclos como uma das propostas de organização do ensino. De acordo com o artigo 23, os sistemas de ensino podem organizarse em séries anuais, períodos semestrais, ciclos, alternância regular de períodos, grupos não seriados, com base na idade, na competência e em outros critérios, ou por forma diversa de organização, sempre que o interesse do processo de aprendizagem assim o recomendar.

A partir de 1996, muitas outras redes de ensino implantaram ou estão implantado os ciclos e a progressão continuada. Nas redes municipais de Betim (MG) e Vitória da Conquista (BA) os ciclos foram implantados em 1998. No ano de 2000, de acordo com dados fornecidos pelas secretarias estaduais de Educação havia as 
seguintes redes de ensino funcionando em ciclos: Bahia - Ciclo Básico nos dois primeiros anos do ensino fundamental; Pará, Amapá, Rio Grande do Norte, Rio de Janeiro, Paraná, Mato Grosso do Sul - os quatro anos do ensino fundamental funcionavam em ciclos; Ceará - todo o ensino fundamental estava organizado em ciclos por faixa etária; Minas Gerais - o ensino fundamental estava organizado em ciclos, mas as escolas podiam optar pela seriação; Mato Grosso - estava implantando os ciclos no ensino fundamental, porém, nas regiões onde os professores não haviam feito a capacitação docente permanecia seriação; São Paulo - adotou os ciclos e a progressão continuada em 1998 (Jacomini, 2002).

De acordo com os dados do MEC/Inep em 2002, 10,9\% das escolas brasileiras tinham o ensino organizado em ciclos, sendo que a maior adesão a essa forma de organização do ensino concentra-se na Região Sudeste, 37,4\%, conforme tabela na página 407 .

Apesar de uma porcentagem ainda pequena, os ciclos e a progressão continuada estão ganhando espaço nas redes públicas de ensino e provocando uma série de reflexões sobre sua legitimidade como mecanismo de democratização da aprendizagem. Embora, grosso modo, entenda-se que aquelas redes de ensino que agruparam várias séries em um período e adotaram durante as séries de cada período a promoção anual independente do desempenho do aluno tenham adotado o que se encontra na literatura com a denominação e o conteúdo de ciclos e progressão continuada, é necessário que seja feita uma ressalva sobre essas diversas experiências, pois nem todas foram implantadas com uma estrutura pedagógica e organizativa que possibilitava democratizar a aprendizagem.

Há casos em que os chamados ciclos constituem-se tão somente no agrupamento de séries, ${ }^{2}$ pois não houve mudanças significativas no tempo, no conteúdo e na avaliação rumo a um novo ordenamento das práticas escolares centradas na aprendizagem de todos. Nesses casos, a progressão continuada adquire a conotação pejorativa, atribuída pelos educadores, de "promoção automática", ${ }^{3}$ ou seja, não existe uma progressão na aprendizagem, mas apenas uma promoção para o ano seguinte do ciclo. Essa condição de implementação dos ciclos tem sido alvo de muitas críticas que, muitas vezes, não distinguem a concepção de organização do ensino que entende a escola como um espaço de democratização do conhecimento, intrínseca aos ciclos e à progressão continuada, das experiências que, embora assim denominadas, não adotaram os pressupostos dessa forma de organização do ensino.

Os resultados poucos promissores em termos de aprendizagem, embora relativamente eficientes em termos de correção de fluxo, têm reforçado a tendência histórica apresentada pelos educadores de se colocarem contra os ciclos e a progressão continuada.

\section{Os educadores e as mudanças educacionais: ciclos ou séries, reprovação anual ou promoção continuada?}

Três problemas centrais perpassam a implantação das políticas educacionais brasileira e formam o cenário no qual são construídas as concepções, opiniões e ações dos educadores: 1) geralmente as propostas são elaboradas sem que se tenha uma avaliação sobre os resultados das políticas que as antecederam;2) raramente elas são discutidas com os educadores e os usuários da escola pública; 3) e, normalmente, não são oferecidas as condições materiais e organizacionais para que elas sejam implemen-

2. As experiências de implementação dos ciclos e da progressão continuadas no Brasil são bastante diversificadas. Em lugares como Porto Alegre, Belo Horizonte e, inicialmente, na rede municipal de São Paulo, os ciclos e a progressão continuada fizeram parte de uma proposta políticopedagógica mais ampla que atendia, pelo menos em parte, às necessidades materiais, institucionais e pedagógicas de seu funcionamento. Porém, outras experiências, como é o caso da rede estadual paulista, os pressupostos político-pedagógicos dos ciclos não estiveram presentes em sua implementação.

3. É necessário esclarecer que em seu sentido original tanto a promoção automática quanto a progressão continuada têm o mesmo sentido, ou seja, acabar com a reprovação anual e estabelecer um processo contínuo de ensino e aprendizagem no decorrer dos oito anos de ensino fundamental. 
Ensino Fundamental

Número de escolas por forma de organização, segundo as Unidades da Federação - 2002

\begin{tabular}{|c|c|c|c|c|c|c|c|c|c|}
\hline \multirow{2}{*}{$\begin{array}{c}\text { Unidade } \\
\text { da } \\
\text { Federação }\end{array}$} & \multirow{2}{*}{ Total Geral } & \multicolumn{2}{|c|}{ Seriado } & \multicolumn{2}{|c|}{ Ciclos } & \multicolumn{2}{|c|}{ Disciplina } & \multicolumn{2}{|c|}{$\begin{array}{l}\text { Mais de uma Forma } \\
\text { de Organização }\end{array}$} \\
\hline & & Total & $\%$ & Total & $\%$ & Total & $\%$ & Total & $\%$ \\
\hline Brasil & 172.508 & 139.060 & 80,6 & 18.723 & 10,9 & 33 & 0,0 & 14.692 & 8,5 \\
\hline Norte & 24.475 & 23.923 & 97,7 & 164 & 0,7 & 0 & 0,0 & 388 & 1,6 \\
\hline Rondônia & 2.453 & $2.270 \mathrm{r} 5$ & 92,5 & 0 & 0,0 & 0 & 0,0 & 183 & 7,5 \\
\hline Acre & 1.554 & 1.554 & 100,0 & 0 & 0,0 & 0 & 0,0 & 0 & 0,0 \\
\hline Amazonas & 4.679 & 4.604 & 98,4 & 28 & 0,6 & 0 & 0,0 & 47 & 1,0 \\
\hline Roraima & 647 & 629 & 97,2 & 15 & 2,3 & 0 & 0,0 & 3 & 0,5 \\
\hline Para & 12.313 & 12.158 & 98,7 & 114 & 0,9 & 0 & 0,0 & 41 & 0,3 \\
\hline Amapá & 643 & 578 & 89,9 & 7 & 1,1 & 0 & 0,0 & 58 & 9,0 \\
\hline Tocantins & 2.186 & 2.130 & 97,4 & 0 & 0,0 & 0 & 0,0 & 56 & 2,6 \\
\hline Nordeste & 81.878 & 73.790 & 90,1 & 2.414 & 2,9 & 17 & 0,0 & 5.657 & 6,9 \\
\hline Maranhão & 12.764 & 12.743 & 99,8 & 1 & 0,0 & 0 & 0,0 & 20 & 0,2 \\
\hline Piauí & 7.428 & 6.927 & 93,3 & 271 & 3,6 & 0 & 0,0 & 230 & 3,1 \\
\hline Ceará & 10.310 & 9.038 & 87,7 & 90 & 0,9 & 1 & 0,0 & 1.181 & 11,5 \\
\hline Rio Grande do Norte & 3.925 & 1.735 & 44,2 & 1.663 & 42,4 & 1 & 0,0 & 526 & 13,4 \\
\hline Paraíba & 6.630 & 6.624 & 99,9 & 3 & 0,0 & 0 & 0,0 & 3 & 0,0 \\
\hline Pernambuco & 10.644 & 10.358 & 97,3 & 229 & 2,2 & 2 & 0,0 & 55 & 0,5 \\
\hline Alagoas & 3.501 & 3.494 & 99,8 & 2 & 0,1 & 0 & 0,0 & 5 & 0,1 \\
\hline Sergipe & 2.255 & 2.252 & 99,9 & 0 & 0,0 & 0 & 0,0 & 3 & 0,1 \\
\hline Bahia & 24.421 & 20.619 & 84,4 & 155 & 0,6 & 13 & 0,1 & 3.634 & 14,9 \\
\hline Sudeste & 37.807 & 17.894 & 47,3 & 14.136 & 37,4 & 6 & 0,0 & 5.771 & 15,3 \\
\hline Minas Gerais & 13.381 & 7.924 & 59,2 & 4.971 & 37,1 & 0 & 0,0 & 486 & 3,6 \\
\hline Espírito Santo & 3.235 & 1.407 & 43,5 & 17 & 0,5 & 0 & 0,0 & 1.811 & 56,0 \\
\hline Rio de Janeiro & 8.020 & 4.198 & 52,3 & 825 & 10,3 & 6 & 0,1 & 2.991 & 37,3 \\
\hline São Paulo & 13.171 & 4.365 & 33,1 & 8.323 & 63,2 & 0 & 0,0 & 483 & 3,7 \\
\hline Sul & 19.825 & 16.588 & 83,7 & 1.523 & 7,7 & 9 & 0,0 & 1.705 & 8,6 \\
\hline Paraná & 6.731 & 4.365 & 64,8 & 1.061 & 15,8 & 6 & 0,1 & 1.299 & 19,3 \\
\hline Santa Catarina & 4.500 & 4.233 & 94,1 & 74 & 1,6 & 1 & 0,0 & 192 & 4,3 \\
\hline Rio Grande do Sul & 8.594 & 7.990 & 93,0 & 388 & 4,5 & 2 & 0,0 & 214 & 2,5 \\
\hline Centro-0este & 8.523 & 6.865 & 80,5 & 486 & 5,7 & 1 & 0,0 & 1.171 & 13,7 \\
\hline Mato Grosso do Sul & 1.117 & 710 & 63,6 & 47 & 4,2 & 0 & 0,0 & 360 & 32,2 \\
\hline Mato Grosso & 2.559 & 1.511 & 59,0 & 372 & 14,5 & 1 & 0,0 & 675 & 26,4 \\
\hline Goiás & 4.113 & 3.919 & 95,3 & 64 & 1,6 & 0 & 0,0 & 130 & 3,2 \\
\hline Distrito Federal & 734 & 725 & 98,8 & 3 & \begin{tabular}{|l|}
0,4 \\
\end{tabular} & 0 & 0,0 & 6 & 0,8 \\
\hline
\end{tabular}

Fonte: MEC/INEP/SEEC

Nota: 0 mesmo estabelecimento pode oferecer mais de um nível/modalidade de ensino. 
tadas a contento. 0 primeiro problema conduz a uma situação muito comprometedora em se tratando de educação, já que as experiências produzem resultados a longo prazo e os erros, geralmente, são irreparáveis, pelo menos, para uma determinada geração. Ou seja, o abandono de uma política educacional e a adoção de outra, sem uma profunda e rigorosa avaliação sobre os erros e acertos, dificultam que os mesmos problemas sejam evitados. Assim, eles tendem a se repetir ao invés de serem resolvidos. 0 segundo problema diz respeito à dificuldade de se implementar uma proposta educacional quando os principais responsáveis pela implementação - os educadores - não a compreendem ou se negam a incorporá-la a sua prática docente. Conhecedor da realidade educacional brasileira, Almeida Júnior, ao discutir a proposta de promoção automática na década de 1950, alertava para a necessidade de "preparar o espírito do nosso professorado e obter sua adesão" (1959, p. 102). Entendia, dessa forma, que sem a compreensão e adesão dos professores não seria possivel modificar as práticas docentes. 0 terceiro problema - a falta de materiais pedagógicos adequados e em número suficiente, o grande número de alunos por sala de aula, ${ }^{4}$ falta de professor ou espaço físico para aula de recuperação paralela, pouco tempo para realização de trabalho coletivo, ausência de organização e desenvolvimento de conteúdos por ciclo de aprendizagem -, além de dificultar a implementação e a produção de bons resultados, constitui-se num dos principais argumentos utilizados pelos educadores para justificarem suas resistências em relação aos ciclos e a promoção continuada, e dele advêm dois condicionantes da resistência dos professores a essa forma de organização do ensino. Um estudo sobre quatro experiências de implantação de ciclos e progressão continuada nas redes públicas de ensino do estado de São Paulo permite verificar os condicionantes ${ }^{5}$ da resistência dos educadores em aceitá-los e implementá-los. Analisaram-se quatro momentos e experiências distintos: a
Reforma de 1967/68, a implantação do Ciclo Básico de Alfabetização (CBA) em 1983/84, a instituição do regime de progressão continuada nos oito anos do ensino fundamental em 1998, na rede estadual do estado de São Paulo, e a adoção dos ciclos e da progressão continuada na rede municipal de ensino da cidade de São Paulo, em 1992.

Para uma melhor compreensão sobre a atuação docente nas quatro experiências aqui apresentadas serão analisados os condicionantes materiais, ideológicos e institucionaispedagógicos da resistência dos educadores a essas propostas educacionais. Os condicionantes materiais da resistência dos educadores aos ciclos e à progressão continuada dizem respeito às condições materiais necessárias ao bom desenvolvimento do processo de ensino e aprendizagem, ou seja, à disposição de espaço físico adequado e suficiente, de materiais pedagógicos necessários, de tempo de discussão entre os educadores, entre outras questões. Os condicionantes ideológicos dizem respeito às concepções e às crenças que são construídas historicamente e determinam a forma de pensar e agir de cada um. No caso deste estudo, as concepções e crenças sobre o processo de ensino e aprendizagem no interior da escola. Os condicionantes institucionais-pedagógicos dizem respeito às condições funcionais e organizativas da escola, bem como a adoção de práticas pedagógicas necessárias ao funcionamento dos ciclos.

4. De acordo com levantamento, World Education Indicators (WEI), realizado pela Unesco em 2000, entre os 45 países ricos e em desenvolvimento avaliados, o Brasil é o que tem o maior número de alunos por professor $(35,6)$ no nível secundário da $7^{a}$ série do ensino fundamental à $3^{a}$ série do ensino médio. Portugal é o que tem o menor (9). A média de aluno por professor nos países desenvolvidos é de 14,3, e nos em desenvolvimento, 21,7. 0 Brasil fica atrás de países como Zimbábue $(24,7)$, Paraguai $(30,6)$ e Filipinas $(34,1)$. Fonte: www. unesco.org/education/information/wer/ htmIENG/talesmenu.

5. A idéia de condicionantes foi desenvolvida por Paro (1996). Neste artigo, a idéia de condicionantes será utilizada para compreender a resistência dos educadores aos ciclos e à progressão continuada. Serão analisados os condicionantes materiais, ideológicos e o institucional/pedagógico (o terceiro é uma denominação própria da autora do texto). 


\section{A Reforma de 1967-1968}

A Reforma de 1967-1968 propôs uma reorganização do ensino primário em termos de conteúdo e o agrupamento das quatro séries em dois níveis ( $1^{\text {a }}$ e $2^{\mathrm{a}} ; 3^{\mathrm{a}}$ e $4^{\mathrm{a}}$ séries), sendo que na passagem da $1^{\text {a }}$ para a $2^{\text {a }}$ série e da $3^{\text {a }}$ para a $4^{\text {a }}$ série a promoção era automática, ou seja, os alunos não eram reprovados. Com o intuito de democratizar o acesso ao ensino ginasial,

os exames de admissão foram unificados e facilitados, e a aprovação dos que a eles compareceram alcançou cerca de 90\%. (Azanha, 1987, p. 96)

Essa medida, democratizante em termos do acesso, provocou críticas por parte dos educadores que entendiam que tal iniciativa implicava o rebaixamento do nível do ensino ginasial. Azanha analisa que os dois principais problemas surgidos durante aquele ano letivo (1968) foram a ameaça de reprovação em massa e as críticas à queda da qualidade do ensino

Um desses problemas é o fantasma das reprovações em massa. Falou-se do rebaixamento do ensino ginasial. (Azanha, 1987, p. 96)

A proposta dos professores, desse nível de ensino, para impedir aquilo que eles entendiam como "perda de qualidade" do ensino ginasial foi a "reprovação em massa", ou seja, pretendia-se reprovar todos aqueles que não atingissem os objetivos ${ }^{6}$ do $1^{\circ}$ ano do ensino ginasial. Essa iniciativa dos professores foi minimizada por uma medida, da Secretaria de Educação, de atribuição de pontos aos professores (para efeito de classificação para atribuição de aulas no ano seguinte) por aluno promovido.

Nessa Reforma, pode-se dizer que os condicionantes se manifestaram da seguinte forma:

Condicionantes materiais: a ampliação do acesso ao ensino ginasial foi feita sem que houvesse o aumento necessário da rede física, fazendo com que muitas escolas funcionassem em condições extremamente precárias (ver Sposito, 1992).

Condicionantes ideológicos: as concepções que os professores tinham do processo de ensino e aprendizagem estavam calcadas numa forma de conceber a escola como um espaço, no qual nem todos poderiam ter sucesso; exigia-se uma produção homogênea, sem considerar as diferenças individuais e tampouco o oferecimento de procedimentos especiais para 0 atendimento dessas diferenças. Entendia-se que o bom desempenho escolar era conseqüência, principalmente, do esforço individual de cada aluno e das condições oferecidas pelas famílias para que a criança ou o adolescente pudessem estar na escola em condições de aprender. Esse conjunto de idéias formado no contexto político-social e pelas próprias experiências escolares dos educadores se chocava com a nova realidade da escola. Os alunos que ingressaram na escola ginasial paulista a partir de 1968 não se encaixam no protótipo de aluno ideal que os professores tinham. Diante desses condicio-nantes ideológicos era necessário uma ampla e intensa preparação do corpo docente para que pudesse compreender e lidar com a nova realidade pedagógica que a reorganização do ensino primário e a unificação dos exames de admissão impunham. Era necessário um trabalho coletivo que desse condições aos professores de repensarem e mudarem suas ideologias, pois as idéias vigentes não eram condizentes à nova realidade. Condicionantes institucionais-pedagógicos: não foram adotadas medidas pedagógicas que pudessem atender as necessidades dos alunos que não possuiam a formação exigida para freqüentar o ginásio, tampouco essas exigências foram redefinidas em função da nova realidade. Esses condicionantes contribuíram

6. Os objetivos do ensino ginasial não haviam sido reorganizados e atualizados em função das novas características que a escola adquiriu ao receber um grande contingente de alunos, cuja preparação recebida no primário não era condizente com a exigida pelos professores do ginásio. 
para fortalecer a posição dos professores de "reprovação em massa". ${ }^{7}$

Esses três condicionantes determinaram uma reação conservadora e, num certo sentido, antidemocrática por parte da maioria dos educadores, ou seja, a adoção da "reprovação em massa" para impedir que a qualidade do ensino ginasial a que estavam acostumados fosse comprometida, penalizava e excluía justamente aqueles que, não fosse o exame de admissão centralizado, não teriam tido acesso àquele nível de ensino.

A atitude dos professores naquele momento, bem como nos outros três que serão analisados a seguir, deve ser compreendida como parte do conservadorismo da própria sociedade, já que a reprodução social exige, em certa medida, a conservação de regras, costumes, formas de pensar, e toda mudança que subverte uma determinada ordem cria um embate político-ideológico por meio do qual os diferentes grupos atuam para manter ou mudar a realidade.

De acordo com o pensamento predominante, entre os professores daquela época, a reprovação dos alunos que não haviam alcançado os objetivos estabelecidos pelo professor, ao final de cada ano letivo, era algo absolutamente normal, pois a reprovação era parte da atividade docente e da vida. A maioria dos educadores e também a sociedade entendiam que a reprovação era de responsabilidade do aluno e de sua família. Na época ainda eram incipientes, entre os professores primários e secundários, as concepções que questionavam essa ideologia.

A não-adequação da escola em termos de conteúdo, método, avaliação, ou seja, a construção de uma cultura escolar que estivesse mais próxima às necessidades e cultura das classes populares, fez com que ela, ao receber esses alunos, os estigmatizasse e produzisse o fracasso escolar a partir de uma interação heterônoma entre a cultura das classes média e alta, que a escola buscava reproduzir, e a cul- tura popular. Os professores formados nesse padrão cultural e, quase sempre, pertencentes à classe média encontraram enorme dificuldade para compreender que a democratização do acesso à escola pública exigia mudanças na forma de pensar a escola, o conhecimento e os direitos sociais.

Como elemento particular da Reforma de 1967-1968 cabe ressaltar o fato de ter ocorrido no período da ditadura militar. Isso, como analisou lisete Arelaro, ${ }^{8}$ contribuiu para reforçar a oposição e a resistência dos educadores, pois tudo que vinha da ditadura era colocado sob suspeita pelos setores democráticos.

Embora essa reforma tenha sido suspensa em 1970, o propósito de ampliar a obrigatoriedade do ensino para oito anos de escolarização, conforme dispositivos constitucionais de 1967, foi consolidado pela Lei $n^{\circ} 5.692 / 71$. Assim, nas décadas de 1970, 1980 e 1990 o acesso à escola pública foi progressivamente ampliado às camadas mais pobres da população, e a dinâmica interna da escola também passou a ser estudada como produtora do fracasso escolar (Patto, 1999).

\section{O Ciclo Básico na rede estadual paulista}

A adoção do Ciclo Básico de Alfabetização (CBA) em 1983-1984 no estado de São Paulo e nos anos seguintes em outros estados brasileiros pretendia enfrentar uns dos mais sérios problemas da escola pública brasileira: a reprovação escolar, especialmente nas séries iniciais. O CBA foi implantado em São Paulo no período de abertura democrática, no governo de Franco Montoro, eleito governador após quase vinte anos de ditadura militar. Havia, portanto, por parte do professorado, fortes expectativas na realização de um processo

7. De acordo com Azanha, "no final de 1968, os índices previstos de reprovação no ginásio eram de $85 \%$ a 90\% na primeira série, ou seja, aquilo que era uma política de Educação estava sendo pedagógica e equivocadamente anulado no âmbito da escola" (1987, p. 115).

8. Entrevista concedida à Rosana Batista Monteiro em 22 e 28/03 de 1967 (conforme Monteiro, 1996). 
democrático de discussão e elaboração das políticas educacionais. As primeiras tentativas nesse sentido demonstraram, na opinião daqueles que estavam à frente da Secretaria de Educação, que os professores mantinham-se conservadores, principalmente em relação às mudanças relativas à prática pedagógica. Dessa forma, a Secretaria de Educação abandonou o processo democrático que havia iniciado, e propôs a implantação do CBA a partir de 1984 . A proposta não foi bem recebida pela maioria dos professores, pois eles entenderam que suas demandas não haviam sido consideradas na formulação de tal política, consideravam que haveria um rebaixamento da qualidade do ensino por causa da promoção continuada da $1^{\mathrm{a}}$ para a $2^{\text {a }}$ série e criticaram duramente a forma autoritária como ela foi implantada.

Já no início de sua implantação, nas reuniões de apresentação e divulgação da proposta, manifestou-se uma forte resistência dos professores, diretores e supervisores de ensino, além de críticas oriundas de diferentes áreas da sociedade.

As mais fortes resistências articularam-se em torno de três questões: o caráter arbitrário da implantação do $\mathrm{CB}$, o perigo de rebaixamento da qualidade do ensino e a questão da avaliação do desempenho do aluno. (Duran, 2003, p. 63)

Assim, os condicionantes da posição que a maioria dos professores adotou em relação ao CBA, podem ser expressos da seguinte maneira:

Condicionantes materiais: não houve garantia de uma estrutura física adequada para a formação de classes menores para que os alunos pudessem ser atendidos pelo professor de modo mais apropriado; e, em muitas escolas, especialmente nas mais periféricas, onde a procura por vagas era maior, não havia espaço físico para as aulas de recuperação em todas as escolas, e nem todas contavam com material adequado e suficiente para o desenvolvimento das novas propostas de alfabetização baseadas nos estudos de Emília Ferreiro. Vale lembrar que na época a maioria das escolas da periferia dos grandes centros urbanos funcionava em quatro turnos devido a grande demanda e o insuficiente número de prédios escolares.

De acordo com avaliação realizada por Zoraide Silva em quatro escolas de São Paulo, os professores e diretores reclamavam, entre outras medidas, da falta de garantias para a instalação e funcionamento dos grupos de apoio nas escolas, reduzir o número de alunos nas classes mais lentas; garantir presença do coordenador pedagógico, dar complementação salarial para os professores alfabetizadores. (1991, p. 52)

Condicionantes ideológicos: como os professores não participaram do processo de discussão e elaboração da proposta do CBA, não puderam iniciar uma reflexão e rever coletivamente suas concepções sobre o ensino-aprendizagem, escolarização das classes populares e democratização do ensino antes do início de sua aplicação. ${ }^{9}$ Houve resistências e dificuldades em compreender e aceitar as novas propostas de alfabetização baseadas nos estudos de Emília Ferreiro e na concepção piagetiana de construção do conhecimento. As idéias tradicionais sobre o que e como se aprende, bem como a metodologia e a avaliação utilizada no processo de ensino-aprendizagem estavam muito arraigadas na prática e no imaginário do professor. Portanto, os professores iniciaram a implementação do CBA com muitos resquícios das idéias de escolarização analisadas nos condicionantes ideológicos da reforma de 1967-1968. Embora a favor da

9. Entende-se que as mudanças ideológicas necessárias à compreensão e adesão às novas práticas não ocorrem a priori, mas no processo. No entanto, compreende-se que a elaboração de uma proposta educacional é um momento singular para que os educadores confrontem suas ideologias com outras concepções e formas de pensar e se preparem para colocá-las em prática. 
democratização do acesso, a maioria dos professores encontrava em seus próprios referenciais ideológicos dificuldades para aceitar que a reprovação era uma barreira à democratização do ensino.

Condicionantes institucionais-pedagógicos: embora a Secretaria de Educação tenha realizado algumas medidas pedagógicas que visavam atender as necessidades criadas pela adoção do CBA no decorrer de sua implementação tais como classe de reforço, ampliação da jornada do aluno na escola, formação continuada para os professores do CBA, criação da função do professor-coordenador do CBA, a partir de 1988, entre outras, elas não foram suficientes para garantir as condições necessárias à realização do propósito de alfabetizar todas as crianças em dois anos.

Dessa forma, como analisou Ambrosetti num estudo sobre o CBA, os professores, por falta de compreensão, ausência de condições para sua implementação, discordância ou a combinação desses fatores, não incorporaram à prática docente os elementos pedagógicos das propostas educacionais.

Colocados como executores de reformas educacionais que não entendem, não aceitam e para cuja elaboração não foram ouvidos, os professores têm atravessado essas mudanças adotando uma atitude que poderíamos definir como "pedagogia do possível”, ou seja, atendem formalmente as exigências oficiais, acrescentam a sua prática aquilo que julgam conveniente, e continuam trabalhando à sua maneira. (Ambrosetti, 1990, p. 58)

Outro aspecto analisado pela autora, e também verificado na implantação dos ciclos na prefeitura de São Paulo em 1992, é a contradição entre a expectativa e o desejo dos educadores de participarem do processo de elaboração das políticas educacionais e a pouca crença que mantêm na possibilidade das soluções para os problemas escolares advirem do interior da própria escola. A expectativa geralmente preponderante é que as autoridades façam alguma coisa para aliviar as difíceis condições do cotidiano escolar.

No entanto, premido pelas difíceis circunstâncias de seu dia-a-dia nas escolas, pela necessidade urgente de ensinar àqueles milhões de alunos que vinham fracassando ano a ano - e repartindo com o professor o seu fracasso - o magistério desejava mais que reflexão e debate. Queria saber o que fazer para melhorar a situação do ensino e, não partilhando da certeza das autoridades de que as soluções poderiam brotar da própria escola, esperava dos órgãos competentes da secretaria ações objetivas e diretrizes para o seu trabalho, além de providências para reverter a desvalorização salarial e social da classe. (lbid., p. 59)

Essa contradição expressava a dificuldade dos educadores se fazerem sujeitos do processo educacional, geralmente não se percebendo como parte do Estado (Sociedade Civil na conceituação de Gramsci), ${ }^{10}$ por isso não acreditavam poderem interferir nas decisões e orientações advindas dos órgãos superiores da Secretaria de Educação, tampouco modificá-las.

\section{Os ciclos e progressão continuada na rede municipal de São Paulo}

Na seqüência cronológica, a próxima experiência a ser analisada é a implantação dos ciclos e da progressão continuada na rede municipal de ensino do município de São Paulo em 1992, na gestão da prefeita Luiza Erundina (PT). Os ciclos e a progressão continuada foram parte da proposta política pedagógica de democra-

10. De acordo com Gramsci "numa concepção mais ampla de Estado entram elementos que também são comuns à sociedade civil, nesse sentido, pode-se dizer que Estado é igual sociedade política mais sociedade civil, ou seja, hegemonia revestida de coerção" (1968, p. 149). 
tização e melhoria da qualidade do ensino municipal. Foi implantado por meio do Regimento Comum das Escolas Municipais no último ano da gestão de Luiza Erundina, em 1992. Embora, inicialmente, a proposta contasse com medidas pedagógicas que poderiam dar sustentação a sua implementação, a política educacional dos governos que se seguiram (Paulo Maluf, Celso Pitta) ${ }^{11}$ não garantiram as condições mínimas necessárias ao funcionamento dos ciclos. Inicialmente, uma parte significativa dos professores opôs-se aos ciclos e à progressão continuada porque considerava que a ausência da reprovação anual por aproveitamento desmotivaria os alunos a estudarem e geraria indisciplina, pois a reprovação anual era vista, por muitos, como um importante instrumento de motivação da aprendizagem e controle da indisciplina (ver Paro, 2001, p. 109). Essa oposição inicial foi reforçada pelas dificuldades que os professores encontraram durante a implementação da progressão continuada para garantir a aprendizagem a todos os alunos.

No caso da experiência municipal de São Paulo os condicionantes da oposição dos educadores aos ciclos e à progressão continuada podem ser expressos da seguinte forma:

Condicionantes materiais: não foram garantidas condições materiais básicas para o funcionamento em ciclos em todas as escolas tais como: menor número de alunos por sala, espaço físico disponível para o funcionamento das Salas de Apoio Pedagógico para os alunos com dificuldade de aprendizagem, salas, horários e professores disponíveis para as aulas de recuperação paralela (ver Jacomini, 2002).

Condicionantes ideológicos: quando os ciclos foram implantados, as idéias sobre democratização do ensino, processo de ensino e aprendizagem, relação professor/aluno, processo de avaliação, conteúdos programáticos, sedimentadas em concepções conservadoras ainda era o que predominava na maioria das escolas. Estava muito presente entre os educadores a ideologia de que a escola, a exemplo da sociedade, deve- ria trabalhar com a seleção dos melhores. Embora tenha havido um esforço, por parte da administração municipal, para envolver os educadores no processo de discussão e elaboração da política educacional, do qual os ciclos fizeram parte, os professores, no geral, sentiram-se à parte desse processo e entenderam a proposta como uma imposição da Secretaria da Educação. 0 processo de elaboração da proposta de ciclos não foi um momento, pelo menos para a maioria dos educadores, de reflexão sobre algumas idéias tradicionais que dificultam que outras formas de perceber e analisar a realidade escolar possam ser construídas. Os educadores tiveram, por exemplo, dificuldade de refletir e rever a ideologia, muito presente, de que para o aluno aprender e se comportar é necessário que o professor utilize instrumentos de punição como a reprovação.

Condicionantes institucionais-pedagógicos: Medidas pedagógicas como reorientação curricular, adoção de uma nova sistemática de avaliação, planejamento e organização do trabalho pedagógico por ciclos, embora iniciadas na gestão de Luiza Erundina, não foram garantidas a contento no decorrer da implantação dos ciclos nas gestões posteriores.

$\mathrm{Na}$ pesquisa sobre os ciclos realizada na rede municipal de São Paulo (Jacomini, 2002), verificou-se que, embora a participação dos educadores na formulação da proposta de ciclos e da progressão continuada propriamente dita tenha sido pequena, a controvérsia expressa nas entrevistas entre os que opinavam que houve participação e aqueles que discordavam refletia, essencialmente, a posição contrária ou a favor aos ciclos. Assim, cabe analisar que, embora seja um fato que os condicionantes materiais e institucionais-pedagógicos reforçam a oposição dos educadores aos ciclos, porque criam situações de ensino e de aprendizagem

11. Também no governo de Marta Suplicy (PT) não foram adotadas, até o momento, medidas significativas que atendam as demandas necessárias ao bom funcionamento do ensino em ciclos e da progressão continuada. 
difíceis e que comprometem o intuito educativo do professor, é necessário considerar que os condicionantes ideológicos, ou seja, as concepções dos educadores sobre educação escolar, formadas no contexto da ideologia dominante, constituem um importante determinante dessa oposição. Isso significa que as resistências aos ciclos e à progressão continuada não podem ser explicadas somente com base nos condicionantes materiais e institucionais-pedagógicos, mas precisam ser analisadas a partir da "arqueologia" que as constitui (ver Paro, 2001).

\section{- regime de progressão continuada na rede estadual de São Paulo}

A última experiência a ser analisada, neste estudo, é a implantação da progressão continuada na rede estadual paulista em 1998. 0 regime de progressão continuada e a organização do ensino fundamental em dois ciclos (Ciclo 1 - os quatro primeiros anos e Ciclo 11 - os quatro últimos anos) foram instituídos pela Resolução SE $n$. 4/98, publicada no Diário Oficial do Estado de São Paulo, em 15 de janeiro de 1998. Os ciclos e a progressão continuada foram parte de uma reforma mais ampla realizada na gestão do ex-governador Mário Covas. A reforma visava a otimização de recursos e uma reestruturação da rede tanto no plano dos órgãos mais centrais, como as antigas delegacias de ensino, rees-truturadas em Delegacias Regionais de Ensino, quanto no plano das escolas, reestruturadas em escolas que atendem crianças do primeiro ciclo do ensino fundamental (da $1^{\text {a }}$ a $4^{\text {a }}$ série do antigo sistema) e escolas que atendem o segundo ciclo (da $5^{\text {a }}$ a $8^{\text {a }}$ série do antigo sistema) e, em alguns, casos o ensino médio.

Alguns estudos que analisaram a reforma da rede estadual paulista constataram que ela foi imposta pela Secretaria de Educação e sofreu fortes resistências dos educadores, dos sindicatos e da população usuária (Freitas, 2000; Adrião, 2001; Steinvascher, 2003).

0 relatório do Conselho Estadual de Educação de São Paulo sobre a Indicação n. 8/
97, que aprovou o regime de progressão continuada, considerou a proposta da Secretaria de Educação uma estratégia que contribui para a universalização da educação básica, visando a permanência das crianças na escola. Também fez referência à eliminação da repetência como forma de otimização dos recursos para um maior e melhor atendimento à população. Esse mesmo relatório orientou a Secretaria de Educação para que estruturasse bem a implantação e a implementação da proposta com ampla participação dos profissionais das escolas e esclarecimento à população. No entanto, as sugestões contidas no relatório não foram seguidas pela Secretaria de Educação, que optou pela implantação do regime de progressão continuada sem consulta e sem participação, seja dos trabalhadores em educação, ou da comunidade usuária. Diante da forma burocrática e autoritária com que o governo do estado conduziu sua implantação e das precárias condições de desenvolvimento do trabalho docente, os educadores construíram uma idéia em torno dos ciclos e da progressão continuada de que ambos visavam somente melhorar as estatísticas sobre a reprovação para ser apresentada ao Banco Mundial, por conta dos acordos e empréstimos. De acordo com Theresa Adrião

a necessidade de "racionalização do fluxo"
é muito mais enfatizada como parte da ne-
cessidade de contenção das perdas de re-
cursos, do que como medida de caráter
pedagógico articulada a uma reorientação
no trato como conhecimento e, por conse-
qüência, com os processos de ensino e de
aprendizagem. (2001, p. 111)

Em relação à experiência paulista de ciclos e progressão continuada pode-se verificar que os condicionantes da resistência dos educadores em relação à proposta se manifestam da seguinte maneira:

Condicionantes materiais: os ciclos e a progressão continuada foram implantados num 
momento em que a Secretaria de Educação havia feito um recadastramento dos alunos visando acabar com os chamados "alunos fantasmas”, o que resultou num enxugamento significativo do número de salas de aula e conseqüentemente na demissão de centenas de professores não efetivos. Não houve diminuição do número de alunos por classe, pelo contrário, em alguns casos aumentou. 0 tempo de trabalho coletivo (HTPC - duas horas semanais), embora garantido na jornada do professor, está bastante aquém do número de horas reivindicado e necessário para que, efetivamente, seja desenvolvido um trabalho coletivo e articulado entre os professores de cada ciclo, e entre os professores de ambos os ciclos (sendo a articulação entre os segundos dificultada pela própria separação física das escolas: Ciclo 1 funcionado em uma escola, Ciclo 11 em outra). Não foram garantidos professores capacitados a contento para a realização de recuperação paralela. A adoção da recuperação de verão, realizada nas férias, não correspondeu às necessidades de um verdadeiro processo de ensino e aprendizagem. As condições salariais dos educadores impedem que eles tenham uma única jornada de trabalho e dessa forma possam dedicar-se adequadamente à atividade pedagógica.

Condicionantes ideológicos: os professores da rede estadual paulista haviam vivenciado a experiência do Ciclo Básico e em certa medida, embora não como rede de ensino, a experiência dos ciclos na rede municipal da cidade de São Paulo, porque muitos professores trabalham em ambas as redes. Tanto num caso como no outro não contavam com uma avaliação sistematizada sobre a pertinência dessa forma de organização do ensino no processo de democratização do conhecimento. Embora possa-se dizer que tenha havido mudanças em relação à forma de pensar o processo de ensino e aprendizagem e a democratização do ensino em relação às primeiras experiências descritas, ainda predominava a concepção de que a função de ensi- nar da escola deve estar permeada pelos mecanismos de seleção por meio da reprovação: seja como recurso didático para pressionar o aluno a estudar, ou como mecanismo para garantir disciplina (como muitas vezes é expresso na fala dos professores), ou ainda para justificar a incapacidade da escola de ensinar a todos. Portanto, a reprovação é concebida como parte intrínseca ao processo de ensino e aprendizagem, a ideologia sedimenta, mesmo que não para o conjunto dos docentes, é que a seleção e a exclusão fazem parte da vida e conseqüentemente é reproduzida na escola. Não havendo um trabalho junto aos professores que permitisse rever essas concepções, elas encontraram terreno fértil para rapidamente se proliferarem e formar uma ampla resistência à progressão continuada.

Condicionantes institucionais-pedagógicos: os ciclos e a progressão continuada não foram acompanhados de uma reorientação curricular que adequasse currículo, processos de avaliação e metodologias de ensino à nova organização do ensino. Na maioria dos casos as escolas continuaram funcionando em séries, sem uma real articulação entre os anos dos ciclos, em termos de conteúdo, avaliação e metodologia. Os tempos e espaços escolares permaneceram os mesmos da seriação.

A ausência de condições materiais adequadas, a não organização pedagógica e institucional da escola para funcionar em ciclos e adotar a não reprovação como princípio pedagógico reforçaram os condicionantes ideológicos criando uma forte resistência dos educadores paulista à promoção continuada. Assim verifica-se que

a proposição política de organização do ensino em ciclos como forma de enfrentar o fracasso escolar nem sempre conta com as medidas necessárias e conseqüentes para a sua realização. Essa condição reforça as resistências dos educadores em mudar suas concepções de ensino, de aprendizagem e de educação e conseqüentemente a adesão 
aos ciclos, ao mesmo tempo em que contribui para a manutenção de uma concepção de escola e de relações sociais construídas historicamente com base numa prática seletiva e de exclusão, e em relações autoritárias e heterônomas. (Jacomini, 2002, p. 70)

Pode-se verificar que os elementos que compõem cada condicionante, em certa medida, se repetem nas quatro experiências analisadas indicando, portanto, por um lado, que pouco se aprende das experiências e, por outro, que a superação dos elementos que caracterizam os três condicionantes analisados demanda tempo e um permanente esforço reflexivo e de ação reivindicatória em torno da construção de uma escola democrática e de qualidade.

\section{Considerações finais}

É comum professores que atuam nas redes de ensino que adotaram ciclos e progressão continuada, especialmente nos casos em que eles se parecem mais a um agrupamento de séries que propriamente ciclos de aprendizagem, afirmarem que são favoráveis a essa forma de organização do ensino como perspectiva de democratização do conhecimento e de superação do fracasso escolar. Porém, consideram que, como não há condições materiais, institucionais e pedagógicas para o seu funcionamento, ela não deveria ser adotada, pois entendem que a promoção continuada comprometeu ainda mais a qualidade do ensino.

Com base nos condicionantes materiais, ideológicos e institucionais-pedagógicos buscou-se construir uma compreensão, entre muitas outras possíveis, sobre como essa posição é formada. Verificou-se que as condições de produção da ação educativa, isto é, os condicionantes materiais e institucionais-pedagógicos converteram-se, muitas vezes, em jus- tificativa da posição adotada pelos educadores. Quando justificam suas opiniões sobre os ciclos e a progressão continuada parecem não considerarem os condicionantes ideológicos, pois não demonstram perceber que suas posições podem estar fortemente determinadas pela forma de pensar e conceber as suas próprias práticas pedagógicas. Assim, não acreditam que são contra a progressão continuada, também porque ela subverte seu modo de pensar a relação professor/aluno, ensino/ aprendizagem, conhecimento/avaliação, e não somente porque não há condições de trabalho que permita colocá-la em prática.

Nesse contexto, os ciclos e a progressão continuada após quase um século de discussões e meio século de experiências encontram-se premidos entre alguns governantes que os vêem apenas como medida burocrática para regularizar o fluxo escolar e economizar os recursos financeiros que são gastos com a reprovação e, educadores, não todos, que atri-buem sua oposição e resistência a essa forma de organização do ensino somente aos condicio-nantes materiais e institucionais-pedagógicos. Dessa forma, acreditam que as críticas e resistências à promoção continuada serão superadas à medida que as condições de ensino e de aprendizagem que eles almejam sejam garantidas. Desconsideram, assim, que parte dessa resistência é determinada pelas concepções de ensino e aprendizagem e democratização da escola que eles construíram no decorrer de suas vidas, ou seja, os condicionantes ideológicos.

Portanto, junto à exigência de que o Estado garanta as condições materiais e institucionais-pedagógicas à consolidação da progressão continuada como prática político-pedagógica de democratização da aprendizagem é necessário uma permanente reflexão dos educadores sobre as ideologias que condicionam suas práticas e dificultam a realização de um processo educativo mais democrático. 


\section{Referências bibliográficas}

ADRIÃO, T. M. de F. Autonomia monitorada como eixo de mudança: padrões de gestão no ensino público paulista (1995-1998). 2001. Tese (Doutorado)- Faculdade de Educação da Universidade de São Paulo, São Paulo, 2001.

ALMEIDA JÚNIOR, A. E a escola primária? São Paulo: Companhia Editorial Nacional, 1959.

AMBROSETTI, N. B. Ciclo Básico: uma proposta vista pelos professores. Cadernos de Pesquisa, São Paulo, n. 75, p. 57-70, nov. 1990.

ARELARO, L. R. G. A ex(tensão) do ensino básico no Brasil: um avesso de um direito democrático. 1988. Tese (Doutorado)Faculdade de Educação da Universidade de São Paulo, São Paulo, 1988.

AZANHA. J. M. P. Educação: alguns escritos. São Paulo: Companhia Editora Nacional, 1987.

BARRETO, E. S. de S.; MITRULIS, E. Os ciclos escolares: elementos de uma trajetória. Cadernos de Pesquisa, São Paulo, n. 108, p. 27-48, 1999.

DURAN, M. C. G. A organização do Ciclo Básico e a concepção de alfabetização: memórias. In: PALMA FILHO, J. C.; ALVES, M. L.; DURAN, M. C. G. Ciclo básico em São Paulo: memórias da educação nos anos 1980. São Paulo: Xamã, 2003.

FREIRE, P. Pedagogia do oprimido. Rio de Janeiro: Paz e Terra, 1987.

FREITAS, J. C. de Cultura e Currículo: uma relação negada pela política do sistema de progressão continuada do Estado de São Paulo. 2000. Tese (Doutorado)- Pontifícia Universidade Católica de São Paulo, São Paulo, 2000.

FUSARI, J. C. et al. As reformas educacionais no Estado de São Paulo: com a palavra os professores. Revista de Educação, São Paulo, n. 13, p. 15-29, abr. 2001.

GRAMSCI, A. Maquiavel: a política e o Estado Moderno. Rio de Janeiro: Civilização Brasileira, 1968.

JACOMINI, M. A. Uma década de organização do ensino em ciclos na rede municipal de São Paulo: um olhar dos educadores. 2002. Dissertação (Mestrado)- Faculdade de Educação da Universidade de São Paulo, São Paulo, 2002.

LEITE, D. M. Promoção automática e adequação do currículo ao desenvolvimento do aluno. Revista Brasileira de Estudos Pedagógicos, Brasília, v. 32, n. 75, 1959.

MAINARDES, J. A organização da escolaridade em ciclos: ainda um desafio para os sistemas de ensino. In: CRESO, F. (Org.). Avaliação, ciclos e promoção na educação. Porto Alegre: Artmed, 2001.

MONTEIRO, R. B. Resgatando o passado: o ciclo básico e a reprodução da reforma do ensino primário de 1967. 1996. Dissertação (Mestrado)- Universidade de Campinas, Campinas, 1996.

PARO, V. H. Por dentro da escola pública. São Paulo: Xamã, 1996.

Reprovação escolar: renúncia à educação. São Paulo: Xamã, 2001.

PATTO, M. H. S. A produção do fracasso escolar: histórias de submissão e rebeldia. São Paulo: Casa do Psicólogo, 1999.

SILVA, Z. I. F. Um estudo avaliativo sobre o ciclo básico de alfabetização em quatro escolas de São Paulo. Avaliação Educacional, São Paulo, n. 3, 1991.

SPOSITO, M. P. 0 povo vai à escola: a luta popular pela expansão do ensino público em São Paulo. São Paulo: Edições Loyola, 1992.

STEINVASCHER, A. A implantação da progressão continuada no Estado de São Paulo: um caminho para a democratização do ensino? 2003. Dissertação (Mestrado)- Faculdade de Educação da Universidade de São Paulo, São Paulo, 2003. 
UNESCO. UNESCO's World Education Indicators (WEI), 2000 (tables as shogun in Appendices II and III of WER 2000). Disponível em: www.unesco.org/education/information/wer/htmIENG/talesmenu.

\section{Obras consultadas}

BRASIL. Lei n. 9.394 de 20 de dezembro de 1996. Diretrizes e Bases da Educação Nacional, Brasília, 1996.

BRASIL. Lei n. 5.692 de 11 de Agosto de 1971. Lei de Diretrizes e Bases para o Ensino de $1^{\circ}$ e $2^{\circ}$ graus, Brasília, 1971.

BRASIL. Lei n. 4.024 de 20 de Dezembro de 1961. Lei de Diretrizes e Bases da Educação Nacional, Brasília, 1961.

Recebido em 28.04.04

Aprovado em 25.08.04

Márcia Aparecida Jacomini é doutoranda em Educação pela Feusp. Pedagoga, psicopedagoga e professora do curso de Pedagogia da Faculdade Taboão da Serra (FTS). Realiza pesquisa sobre organização do ensino em ciclos e progressão continuada. 